\title{
case Report \\ Successful Balloon-assisted Coil Embolization of Right Subclavian Artery Aneurysm: A Case Report
}

Mai Nampei, ${ }^{1,2}$ Masato Shiba, ${ }^{2}$ Hiroshi Sakaida, ${ }^{2}$ Yoshinari Nakatsuka, ${ }^{2}$ Ryuta Yasuda, ${ }^{2}$ Naoki Toma, ${ }^{2}$ and Hidenori Suzuki

Objective: Subclavian artery aneurysms are relatively rare, and have been treated by open surgery and/or endovascular treatment using a stent graft. In this article, we report a case of unruptured right subclavian artery aneurysm successfully treated using balloon-assisted coil embolization.

Case Presentation: A 77-year-old man was diagnosed with an asymptomatic unruptured right subclavian artery aneurysm of $8 \mathrm{~mm}$ in diameter by follow-up CTA after surgery for thoracoabdominal aortic aneurysms. He also had a history of cerebral infarction and clipping of an unruptured cerebral aneurysm. The subclavian artery aneurysm was treated by balloon-assisted coil embolization because its diameter increased to $17.6 \mathrm{~mm}$ in 2 years. Balloon assistance was mainly used to prevent protrusion of the framing coil into the parent artery, and satisfactory framing was achieved. Subsequently, the aneurysm was obliterated using filling and finishing coils. The postoperative course was uneventful, and the follow-up MRI at 18 months after treatment revealed no recanalization of the aneurysm.

Conclusion: Balloon-assisted coil embolization may be an effective treatment for subclavian artery aneurysms, but further long-term follow-up and case accumulation are needed.

Keywords subclavian artery aneurysm, balloon-assisted coil embolization, endovascular, total arch replacement

\section{Introduction}

Subclavian artery aneurysms are relatively rare, accounting for $0.13 \%$ of all aneurysms. ${ }^{1)}$ Most of the subclavian artery aneurysms have been treated by open surgery or endovascular treatment using a stent graft. ${ }^{2,3)}$ A case report of stent-assisted coil embolization was previously published, ${ }^{4)}$ but to the best of our knowledge, no study has reported balloon-assisted coil embolization of subclavian artery aneurysms. In this article, we report a case of

${ }^{1}$ Department of Neurosurgery, Saiseikai Matsusaka General Hospital, Matsusaka, Mie, Japan

${ }^{2}$ Department of Neurosurgery, Mie University Graduate School of Medicine, Tsu, Mie, Japan

Received: July 12, 2019; Accepted: March 12, 2020

Corresponding author: Mai Nampei. Department of Neurosurgery, Saiseikai Matsusaka General Hospital, 1-15-6 Asahi-cho, Matsusaka, Mie 515-8557, Japan

Email: m.nampei.n@gmail.com

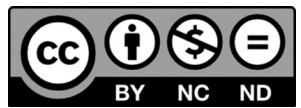

This work is licensed under a Creative Commons Attribution-NonCommercialNoDerivatives International License.

(C)2020 The Japanese Society for Neuroendovascular Therapy unruptured right subclavian artery aneurysm successfully treated using balloon-assisted coil embolization.

\section{Case Presentation}

A 77-year-old man, who had a history of hypertension, cerebral infarction (etiology: unclear), and clipping of an unruptured left middle cerebral artery aneurysm. He had undergone artificial vascular graft replacement for thoracic and abdominal aortic aneurysms 7 and 5 years previously, respectively. Since then, follow-up computed tomography angiography (CTA) had been regularly performed. Two years ago, CTA revealed a saccular right subclavian artery aneurysm measuring approximately 8 $\mathrm{mm}$ in diameter. Because there was an increase in the aneurysmal size, he was referred to our department. On the initial consultation, his consciousness was clear and there was no neurological deficit. There was no ischemic symptom of the right upper limb, no laterality in the blood pressure measured on the brachium, and no history of trauma.

Thoracic CTA revealed a saccular aneurysm measuring approximately $18 \mathrm{~mm}$ in diameter on the dorsal side of the 

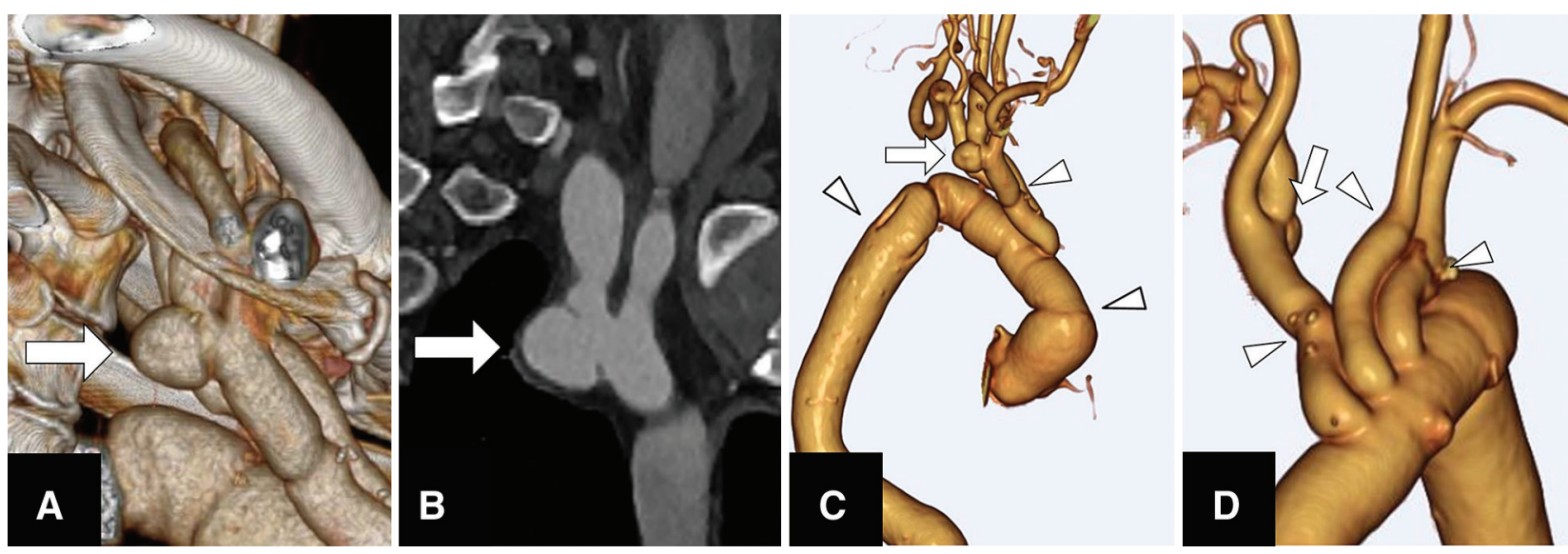

Fig. 1 Preoperative 3D-CTA. A saccular aneurysm (arrow) is detected on the dorsal side of the right subclavian artery origin (A: 3D, B: sagittal section). The arrow head indicates the site of aortic arch graft anastomosis (C: 3D right lateral view, D: 3D frontal view). 3D: threedimensional; CTA: computed tomography angiography

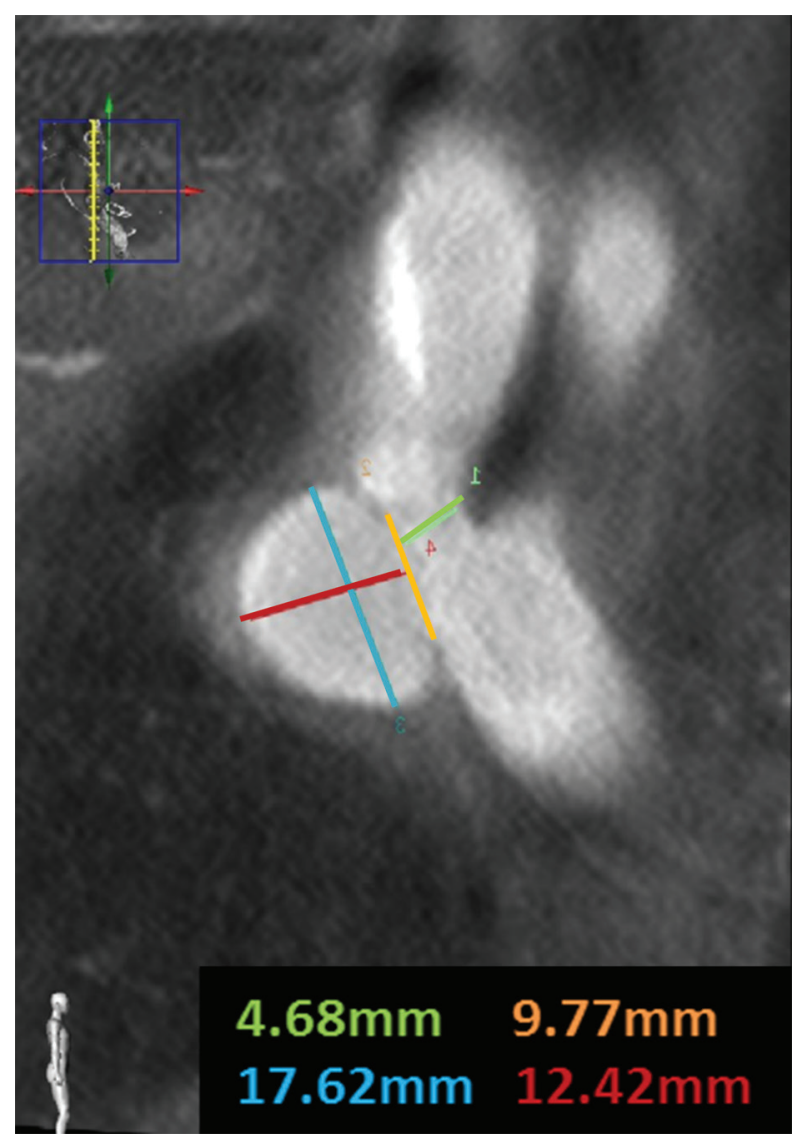

Fig. 2 Preoperative right subclavian arteriography (maximum intensity projection image). The aneurysm measures $17.6 \mathrm{~mm}$ in maximum diameter and $9.8 \mathrm{~mm}$ in neck diameter. The diameter of the parent artery distal to the neck is $4.7 \mathrm{~mm}$, and slight stenosis is noted.

right subclavian artery origin (Fig. 1). In addition, the ascending to descending aortas had been replaced with artificial vascular graft, and a portion of the brachiocephalic artery had been anastomosed (Fig. 1). Ultrasonography suggested an aneurysm, but noise made detailed assessment difficult. On subclavian arteriography, the maximum and neck diameters of the aneurysm were $17.6 \mathrm{~mm}$ and $9.8 \mathrm{~mm}$, respectively. Slight stenosis of the parent artery was observed (Fig. 2).

Endovascular treatment was selected through a cooperative conference by several departments, including the Department of Cardiovascular Surgery. As antithrombotic therapy, aspirin at $100 \mathrm{mg} / \mathrm{day}$, which had been administered after artificial vascular graft replacement, was continued.

Under local anesthesia, a 4-Fr, 100-cm SY5 catheter (Hanako Medical, Saitama, Japan) was inserted through the left radial artery, and a 6-Fr, 55-cm Ansel ANL1 catheter (Cook, Bloomington, IN, USA) was inserted through the right brachial artery. Initially, the SY 5 was inserted into the right brachiocephalic artery for diagnostic imaging. Three-dimensional (3D) rotational angiography was performed, and a working angle was established. Subsequently, the Ansel end was inserted into the distal subclavian artery. Intravascular ultrasonography was performed, but the vascular diameter was large, and no detailed information on the aneurysmal neck was obtained. Using a 0.014-inch 200-cm CHIKAI guidewire (Asahi Intecc, Aichi, Japan), a SHOURYU 7-7 mm balloon (Kaneka Medix Corp., Osaka, Japan) was guided to the aneurysmal neck for the balloon-assisted technique. A PX SLIM 045 microcatheter (Penumbra, Alameda, CA, USA) was inserted into the aneurysm under guidance with 0.010/0.014-inch 200-cm TENROU guidewire (Kaneka 


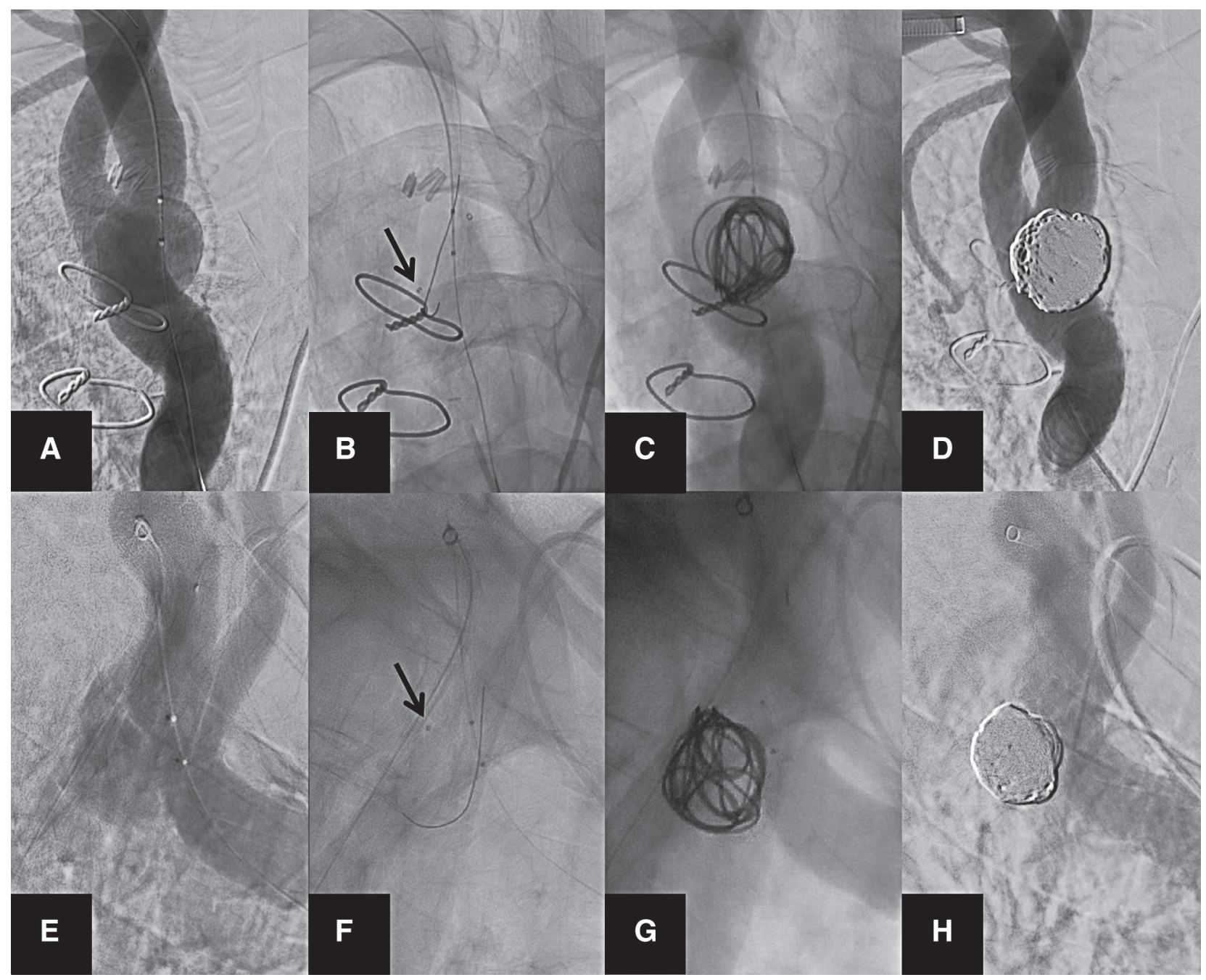

Fig. 3 Intraoperative angiography (A-D: anteroposterior views, E-H: lateral views). (A and E) A balloon is guided to the aneurysmal neck. (B and F) A catheter is inserted into the aneurysm through the outflow zone of the aneurysm such that its end (arrow) faces the inflow zone. (C and $\mathbf{G}$ ) The first coil is inserted into the aneurysm to prepare a frame. (D and $\mathbf{H}$ ) Final angiography confirms complete obliteration and the patency of the parent artery.

Medix Corp., Osaka, Japan) (Fig. 3). Framing was performed using a Penumbra coil 400 complex standard 18 mm-57 cm (Penumbra, Alameda, CA, USA). The coil was inserted while preventing coil protrusion by inflating the SHOURYU, which had been inserted to cover the aneurysmal neck on the distal side at an appropriate time, resulting in favorable frame formation. Next, filling was carried out using Penumbra coils 400 complex standard $16 \mathrm{~mm}-60 \mathrm{~cm}$ and $14 \mathrm{~mm}-50 \mathrm{~cm}$, and Penumbra coils 400 complex soft $12 \mathrm{~mm}-35 \mathrm{~cm}, 10 \mathrm{~mm}-30 \mathrm{~cm}, 8 \mathrm{~mm}-20 \mathrm{~cm}, 7 \mathrm{~mm}-20 \mathrm{~cm}$, $6 \mathrm{~mm}-15 \mathrm{~cm}$, and $5 \mathrm{~mm}-13 \mathrm{~cm}$. At this point, the "kickback" phenomenon of the PX SLIM 045 was noted, and the procedure was completed. During filling, no balloon was used. Final angiography confirmed that the aneurysm involving the inflow zone was tightly embolized (complete obliteration, packing density: $35.5 \%$ ), and that the parent artery was patent.

There were no neurological abnormalities during or after surgery. For postoperative antithrombotic therapy, aspirin at $100 \mathrm{mg} /$ day, which had been administered before treatment, was continued. Postoperative brain magnetic resonance imaging (MRI) did not demonstrate new-onset cerebral infarction. The postoperative course was uneventful, and the patient was discharged from the hospital on the ninth postoperative day. Plain X-ray 1 month after treatment, CTA/ultrasonography after 2 months, plain X-ray after 4 months, and subclavian arteriography (Fig. 4) after 6 months confirmed that there was neither change in the coil shape nor aneurysmal recanalization, and that the parent artery was patent. In addition, CTA after 14 months and 


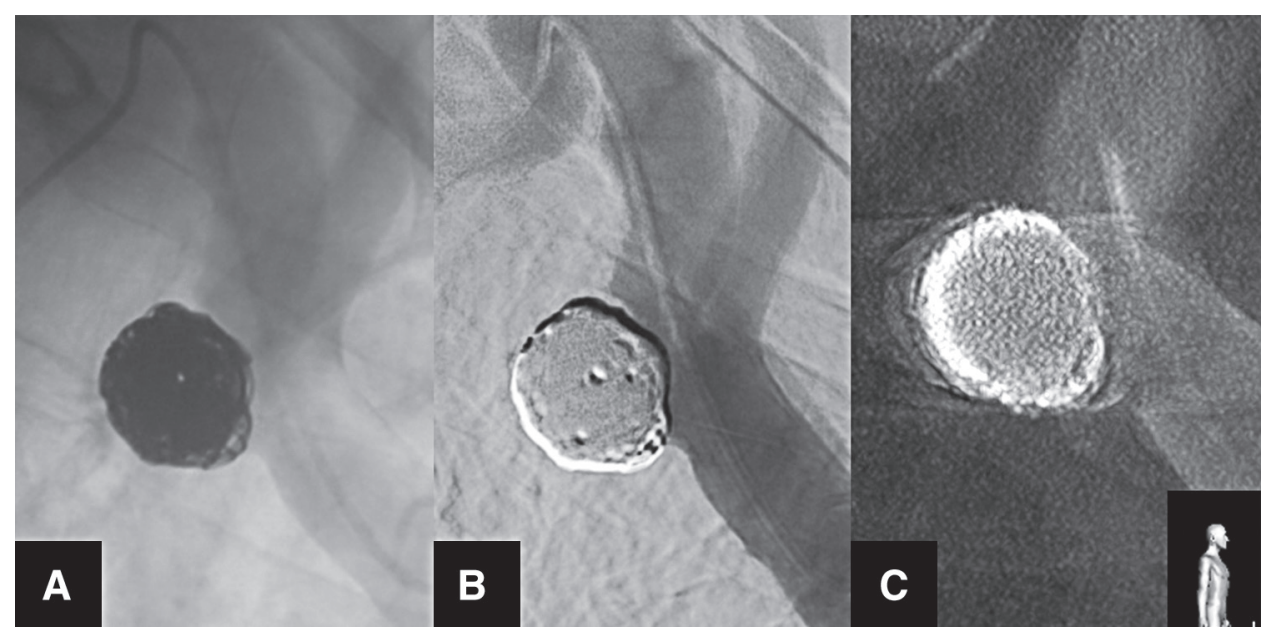

Fig. 4 Subclavian arteriography 6 months after surgery. There is no recanalization of the aneurysm. The parent artery is patent (A: before subtraction, B: after subtraction, C: 3D rotational angiography). 3D: three-dimensional

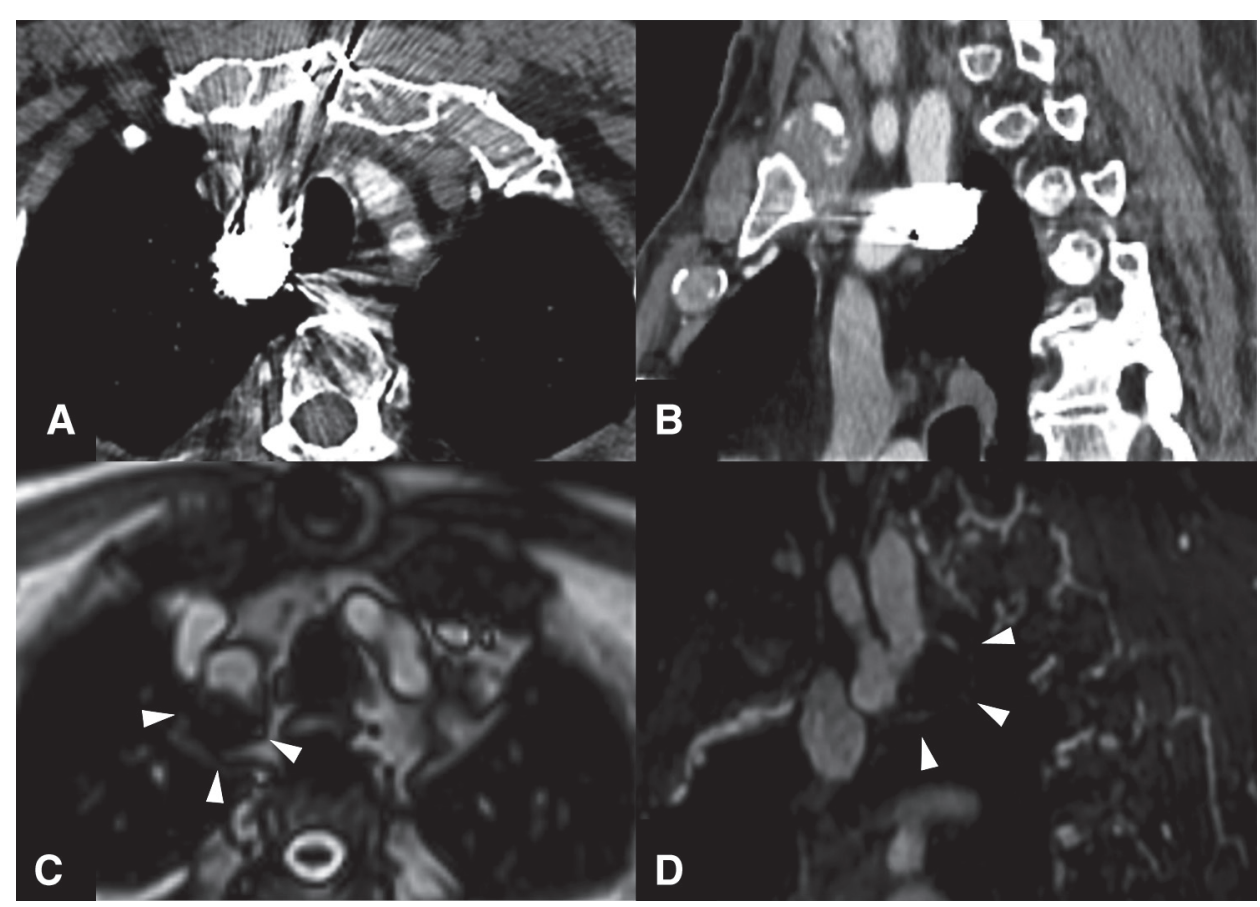

Fig. 5 CTA 12 months after surgery (A: axial section, B: sagittal section) and CINE MRI after 18 months (C: axial section, D: sagittal section). On CTA, detailed evaluation of the aneurysmal neck is difficult due to coil artifacts, but parent artery blood flow is maintained. MRI confirms no change in the embolic state of the aneurysm (arrow head). CTA: computed tomography; MRA: magnetic resonance angiography

MRI after 18 months confirmed no change in the state of embolization (Fig. 5).

\section{Discussion}

Subclavian artery aneurysms are relatively rare, and etiological factors for these aneurysms include arteriosclerosis, trauma, and thoracic outlet syndrome. Several previous studies reported connective tissue disease, collagen disease, iatrogenic factors (mis-puncture on central vein), and infection as etiological factors, and suggested that some patients had idiopathic aneurysms.,5) The incidence of subclavian artery aneurysms complicated by aneurysms at other sites is high $(33-47 \%),{ }^{7)}$ and the preoperative assessment of systemic blood vessels is important. In addition, aneurysm development during the course must also be 
considered. Our patient had undergone treatment for middle cerebral artery and thoracic/abdominal aortic aneurysms. Etiological factors for multiple aneurysms include connective tissue disease and infectious aneurysms. However, in the present case, neither physical nor laboratory findings suggested these disorders. Furthermore, the aneurysmal site was distant from the anastomotic site of artificial vascular graft, but the possibility of an iatrogenic aneurysm was unable to be excluded.

Approximately $50 \%$ of subclavian artery aneurysms are detected in the absence of symptoms/signs. ${ }^{8)}$ On the other hand, according to a report published by Vierhout et al. involving 381 patients, local signs, such as pulsatile masses, accounted for $51 \%$ of signs, aneurysm enlargement-related mass effects (hoarseness, brachial plexopathy, airway stenosis, and vascular stenosis) for 36\%, intra-aneurysmal thrombus-related distal thromboembolism for $22 \%$, and aneurysmal rupture-related hemoptysis or hemothorax for $9 \% .{ }^{5)}$ If rupture occurs, it may lead to a fatal outcome, as demonstrated for other aneurysms.

There are no criteria for treatment indications. However, the incidence of thromboembolism was reported to be $9-22 \%, 5,9)$ and another study suggested that rupture occurs in $40 \%$ of patients treated conservatively. ${ }^{10)}$ Based on these studies, some investigators emphasized the necessity of surgical intervention regardless of the aneurysmal diameter. ${ }^{11,12)}$ The present case was asymptomatic, but the aneurysmal size markedly increased during the 2-year follow-up, with a maximum diameter of $18 \mathrm{~mm}$. Therefore, we decided to perform surgery to prevent the aneurysm-related complications.

Subclavian artery aneurysms have been treated by open surgery or stent grafting in many cases. Endovascular surgery by stent-assisted coil embolization has also been reported. ${ }^{2-4)}$ Reports on subclavian artery aneurysms after 2018 are shown in Table 1. ${ }^{3,13-22)}$ Treatment methods consisted of open surgery in 25 patients, endovascular treatment in 13 , and their combination in 3. Endovascular treatment procedures consisted of stent grafting in 12 patients, stenting in 2, stent-assisted coil embolization in 1, and coil embolization in 1 . To the best of our knowledge, this is the first report of a subclavian artery aneurysm treated using balloon-assisted coil embolization. The etiology (thoracic outlet syndrome, trauma), aneurysmal site (intra-/ extrathoracic), and complications are important for determining a treatment method. In each treatment method, the importance of maintaining cerebral blood flow is recognized. In particular, right subclavian artery aneurysms are adjacent to the right common carotid artery in some cases; therefore, a treatment strategy in which attention is paid to cerebral blood flow maintenance is necessary. ${ }^{2}$ In the present case, endovascular treatment under local anesthesia was considered to be more appropriate than open surgery under general anesthesia due to advanced age, hypertension, and the possibility of tissue adhesion after graft replacement for thoracic/abdominal aortic aneurysms. Parent artery-preserving endovascular treatment methods for aneurysms include covered stenting such as stent grafting, coil embolization, and stenting alone. ${ }^{4)}$ Coil embolization procedures include embolization with a coil alone, balloon-assisted coil embolization, and stent-assisted coil embolization. Based on the site, shape, and characteristics of aneurysms, an optimal method is selected. In treatment with a stent graft, which has been introduced in many studies, a main blood vessel adjacent to the aneurysm may be occluded. To avoid this, several methods have been performed. Funata et al. ${ }^{11)}$ and Hosokawa et al. ${ }^{12)}$ reported a hybrid procedure in which stent grafting for right subclavian artery aneurysms was combined with axillo-axillar crossover bypass. The hybrid procedure facilitates the prevention of common carotid artery or vertebral artery blood flow blockage, and is less invasive than open surgery by median sternotomy approach. However, it is more invasive than endovascular surgery alone, which was performed in the present case. When performing endovascular surgery alone, coil migration or failure in coil filling may occur during coil embolization of wide-neck aneurysms. In the present case, balloon- or stent-assisted procedures were considered to prevent these. As advantages of the stent-free balloon-assisted procedure, potent antithrombotic therapy is unnecessary, and there may be no procedure-related problems, such as stent injury/ interference, when endovascular operations at this site are required to treat other lesions later. This disease is complicated by several aneurysms in many cases, and the possibility that several sessions of surgery may be required must be considered. In the present case, slight stenosis of the parent artery was observed, and we considered stent insertion to reduce aneurysmal stress related to blood stagnation at this area as an option, but instead selected a treatment strategy to initially complete the balloon-assisted procedure alone, if possible, and additionally perform stenting if recurrence was noted considering the risk of stent injury/interference under additional endovascular operations. We performed this procedure using an approach through the right upper limb, in which the risk of graft injury may be the lowest considering the state after aortic arch and abdominal aorta 
Table 1 Summary of subclavian artery aneurysms reported between 2018 and 2019

\begin{tabular}{|c|c|c|c|c|c|c|c|c|c|c|}
\hline & Investigator & $\begin{array}{l}\text { Year of } \\
\text { report }\end{array}$ & Age & Sex & Etiology & Site & $\begin{array}{c}\text { Maximum } \\
\text { diameter }(\mathrm{mm})\end{array}$ & $\begin{array}{l}\text { Presence of } \\
\text { symptom }\end{array}$ & Clinical presentation & Treatment \\
\hline 1 & $\mathrm{D}^{\prime}$ Oria $\mathrm{M}^{13)}$ & 2018 & 69 & M & No description & Intrathoracic, right & 30 & Asymptomatic & & $\begin{array}{l}\text { Hybrid (bypass + } \\
\text { stent graft) }\end{array}$ \\
\hline 2 & Oh JK ${ }^{14)}$ & 2018 & 72 & M & No description & Intrathoracic, right & 35 & Asymptomatic & & $\begin{array}{l}\text { Stent-assisted coil } \\
\text { embolization }\end{array}$ \\
\hline 3 & Pallett SJC ${ }^{15)}$ & 2018 & 28 & M & Trauma & Extrathoracic, left & No description & Symptomatic & $\begin{array}{l}\text { Claudication of the left } \\
\text { upper limb }\end{array}$ & Open surgery \\
\hline 4 & Li Li) & 2018 & 32 & M & Behcet's disease & Extrathoracic, left & No description & Symptomatic & $\begin{array}{l}\text { Left cervical pain, left } \\
\text { shoulder pain }\end{array}$ & Stent graft \\
\hline 5 & Franz RW' ${ }^{16)}$ & 2018 & 61 & M & Possibility of trauma & Intrathoracic, right & 72 & Symptomatic & $\begin{array}{l}\text { Left thoracic/abdominal } \\
\text { pain }\end{array}$ & Stent graft \\
\hline 6 & Kaneyuki $D^{17)}$ & 2018 & 20 & M & $\begin{array}{l}\text { Fibromuscular } \\
\text { dysplasia }\end{array}$ & Extrathoracic, left & 25 & Asymptomatic & & Open surgery \\
\hline 7 & El Khoury $\mathrm{R}^{18)}$ & 2019 & 79 & M & Trauma & $\begin{array}{l}\text { No description of } \\
\text { intra- or extrathoracic } \\
\text { sites, left }\end{array}$ & 21 & Asymptomatic & & Stent \\
\hline \multirow[t]{3}{*}{8} & \multirow[t]{3}{*}{ Davidovic LB $^{19)}$} & \multirow[t]{3}{*}{2019} & \multirow[t]{3}{*}{$42.84 \pm 14.66$} & \multirow{3}{*}{$\begin{array}{l}\text { M: } 17 \\
\text { F: } 8\end{array}$} & \multirow{3}{*}{$\begin{array}{l}\text { Thoracic outlet } \\
\text { syndrome: } \mathrm{n}=18 \\
\text { Arteriosclerosis: } \mathrm{n}=5 \\
\text { Trauma: } \mathrm{n}=2\end{array}$} & Intrathoracic, right: $\mathrm{n}=2$ & \multirow[t]{3}{*}{ No description } & \multirow{2}{*}{$\begin{array}{l}\text { Symptomatic: } n=3 \text {, } \\
\text { Asymptomatic: } n=2\end{array}$} & \multirow{2}{*}{$\begin{array}{l}\text { Dyspnea: } \mathrm{n}=1 \text {, } \\
\text { Hemothorax: } \mathrm{n}=2\end{array}$} & Open surgery: $\mathrm{n}=2$ \\
\hline & & & & & & Intrathoracic, left: $\mathrm{n}=3$ & & & & $\begin{array}{l}\text { Open surgery: } n=2 \text {, } \\
\text { hybrid (bypass }+ \\
\text { stent graft): } n=1\end{array}$ \\
\hline & & & & & & $\begin{array}{l}\text { Extrathoracic, } n=20 \text {, } \\
\text { no description of the } \\
\text { left or right }\end{array}$ & & $\begin{array}{l}\text { Symptomatic: } \mathrm{n}=19 \text {, } \\
\text { Asymptomatic: } \mathrm{n}=1\end{array}$ & $\begin{array}{l}\text { Shoulder pain and pulsatile } \\
\text { mass: } n=7 \text {, acute limb } \\
\text { ischemia: } n=5 \text {, chronic } \\
\text { limb ischemia: } n=7\end{array}$ & $\begin{array}{l}\text { Open surgery: } n= \\
19, \text { stent graft: } n=1\end{array}$ \\
\hline 9 & Gillen J20) & 2019 & 47 & M & Arteriosclerosis & Intrathoracic, right & 27 & Symptomatic & Right upper limb pain & $\begin{array}{l}\text { Hybrid (bypass + } \\
\text { coil embolization) }\end{array}$ \\
\hline 10 & Ramtoola $\mathrm{MT}^{21)}$ & 2019 & 74 & M & Arteriosclerosis & Intrathoracic, right & No description & $\begin{array}{l}\text { Symptomatic } \\
\text { (rupture) }\end{array}$ & $\begin{array}{l}\text { Shortness of breath, } \\
\text { back pain }\end{array}$ & Stent \\
\hline 11 & Archie $\mathrm{MM}^{22)}$ & 2019 & $\begin{array}{l}\text { Mean } 39 \\
(17-66)\end{array}$ & $\begin{array}{l}\mathrm{M}: 4 \\
\mathrm{~F}: 3\end{array}$ & $\begin{array}{l}\text { Thoracic outlet } \\
\text { syndrome }\end{array}$ & $\begin{array}{l}\text { No description of intra- or } \\
\text { extrathoracic sites, right: } \\
n=2 \text {, left: } n=5\end{array}$ & $\begin{array}{l}\text { Mean 21 } \\
(20-22)\end{array}$ & Symptomatic: $\mathrm{n}=7$ & Limb ischemia: $n=7$ & Stent graft: $\mathrm{n}=7$ \\
\hline 12 & Present case & 2019 & 77 & M & Unclear & Intrathoracic, right & 18 & Asymptomatic & & $\begin{array}{l}\text { Balloon-assisted } \\
\text { coil embolization }\end{array}$ \\
\hline
\end{tabular}


grafting. Indeed, when coil embolization was started, the aneurysmal neck was relatively narrow, and a coil was able to be placed in the aneurysm through balloon-assisted operations alone at appropriate times. Furthermore, the parent artery measured $\geq 4 \mathrm{~mm}$ in diameter, and the aneurysmal neck diameter was $9.8 \mathrm{~mm}$, but a SHOURYU 7-7 mm was used. We assumed that the aneurysmal shape would facilitate coil stabilization, even if the aneurysmal neck was not completely covered by the balloon, if it prevents protrusion of the framing coil into the parent artery. A stent was prepared in case that treatment was unable to be completed by balloon-assisted coil embolization alone, but it was not used.

To the best of our knowledge, there was no study that reported the treatment of subclavian artery aneurysms by balloon-assisted coil embolization. The long-term outcome remains to be clarified. However, Oh et al. ${ }^{14)}$ reported a patient in whom stent-assisted coil embolization was performed, and there was no recurrence during the 3-year postoperative follow-up. In the present case, there has been no recurrence during the 1-year-and-6-month follow-up. On the other hand, a postoperative aneurysmal rupture which occurred 1 year and 7 months after the coil embolization was reported. ${ }^{23)}$ When rupture is suspected, it is difficult to evaluate the aneurysmal diameter or embolic state on CT due to coil artifacts; therefore, subclavian arteriography must be performed in the early phase. ${ }^{23)}$ In the present case, the postoperative course during the 1-year-and-6-month follow-up has been uneventful. However, to evaluate the long-term efficacy of coil embolization, further follow-up and case accumulation are necessary.

\section{Conclusion}

We performed balloon-assisted coil embolization of a right subclavian artery aneurysm after total aortic arch replacement, and obtained favorable outcome. This treatment method for subclavian artery aneurysms is minimally invasive and does not require blood flow blockage, differing from open surgery. In addition, there is no influence on cerebral blood flow during surgery; therefore, this method may be a useful treatment strategy. To clarify the long-term usefulness of this method, further long-term follow-up and case accumulation are necessary.

\section{Disclosure Statement}

We declare no conflict of interest regarding this article.

\section{References}

1) Dent TL, Lindenauer SM, Ernst CB, et al: Multiple arteriosclerotic arterial aneurysms. Arch Surg 1972; 105: 338-344.

2) Yamazaki M, Hachiya T, Yamashiro M, et al: Successful surgical treatment of right subclavian artery aneurysm: report of two cases. Heart 2014; 46: 620-626.

3) Li L, Gu Y, Qi L: Endovascular repair of a subclavian artery aneurysm in Behçet's disease. Interact Cardiovasc Thorac Surg 2018; 27: 461-462.

4) Matsumoto S, Nakahara I, Higashi T, et al: Successful combination therapy with parallel stent -graft placement and coil embolization for a treatment of a fusiform brachiocephalic artery aneurysm: a case report. JNET J Neuroendovasc Ther 2008; 2: 56-61.

5) Vierhout BP, Zeebregts CJ, van den Dungen JJ, et al: Changing profiles of diagnostic and treatment options in subclavian artery aneurysms. Eur J Vasc Endovasc Surg 2010; 40: 27-34.

6) McCollum $\mathrm{CH}$, Da Gama AD, Noon GP, et al: Aneurysm of the subclavian artery. J Cardiovasc Surg 1979; 20: 159-164.

7) Coselli JS, Crawford ES: Surgical treatment of aneurysms of the intrathoracic segment of the subclavian artery. Chest 1987; 91: 704-708.

8) Shah A, Katz ES, Stern A, et al: Isolated subclavian artery aneurysm: evaluation by transesophageal echocardiography. Echocardiography 2004; 21: 73-76.

9) Dougherty MJ, Calligaro KD, Savarese RP, et al: Atherosclerotic aneurysm of the intrathoracic subclavian artery: a case report and review of the literature. J Vasc Surg 1995; 21: 521-529.

10) Austin EH, Wolfe WG: Aneurysm of aberrant subclavian artery with a review of the literature. $J$ Vasc Surg 1985; 2: 571-577.

11) Funata $S$, Uchida $T$, Hamasaki A, et al: Endovascular treatment of intrathoracic right subclavian artery aneurysm after cardiac surgery. Jpn Vasc Surg 2016; 25: 177-180.

12) Hosokawa $Y$, Onitsuka $S$, Tobinaga $S$, et al: Hybrid treatment of the intrathoracic right subclavian artery aneurysm. Jpn J Cardiovasc Surg 2014; 43: 270-273.

13) D’Oria M, Pipitone M, Chiarandini S, et al: Hybrid treatment of a true right subclavian artery aneurysm involving the vertebral artery using a covered stent. Ann Vasc Surg 2018; 53: 273.e7-273.e11.

14) Oh JK, Lee JH: Bidirectional transradial and transfemoral approach for stent-assisted coil embolization of right subclavian artery saccular aneurysm. Vasc Endovascular Surg 2018; 52: 565-568.

15) Pallett SJC, Singh I, Rady N, et al: Delayed subclavian artery aneurysm following fixation of a clavicular fracture. Vasc Endovascular Surg 2018; 52: 459-462. 
16) Franz RW, Fraser SR: Endovascular repair of incidentally found subclavian artery aneurysm: a case report from an urban level 1 trauma center. Vasc Endovascular Surg 2018; 52: 382-385.

17) Kaneyuki D, Ueda H, Matsumiya G: Right subclavian artery aneurysms with fibromuscular dysplasia. Ann Vasc Surg 2018; 48: 253.e7-253.e9.

18) El Khoury R, Greenspahn BR, Jacobs CE, et al: Minimally invasive repair of left subclavian artery aneurysm. Cardiovasc Revasc Med 2019 May 22 [Epub ahead of print]. doi: 10.1016/j.carrev.2019.05.013.

19) Davidovic LB, Zlatanovic P, Ducic $S$, et al: Single center experience in the management of a case series of subclavian artery aneurysms. Asian J Surg 2019; 43: 139-147.
20) Gillen J, Tse L, Berg A, et al: Hybrid repair of an intrathoracic bilobed subclavian artery aneurysm. Ann Vasc Surg 2019; 59: 312.e11-312.e14.

21) Ramtoola MT, Bhatti M, Shetty R: A case report of a ruptured subclavian artery aneurysm presenting to the emergency department. Clin Case Rep 2019; 7: 797-800.

22) Archie MM, Gelabert HA: Endovascular reconstruction of subclavian artery aneurysms in patients with arterial thoracic outlet syndrome. Ann Vasc Surg 2019; 57: $10-15$.

23) Terada S, Tabuchi M, Yamauchi A: Rupture of saccular brachiocephalic artery aneurysm after one year and seven months from coil embolization; report of a case. Kyobu Geka 2016; 69: 959-962. (in Japanese) 